\title{
Artificial Intelligence in Finance and Accounting
}

\section{Reepu}

\begin{abstract}
Abstract: Today's workplace has been amassed by human as well as digital workforce. There have been recurrent modifications in over digital landscape. Artificially intelligent bots have begun transform the notions of many. Finance and Accounting finds its applications in different industry domains. Now-a-days Digital workforce mimics the human workforce. They not only finish the assigned task rapidly but also supplement it with accuracy and vividness. The present paper is an attempt to discuss that how Artificial Intelligence is an additive to Human Brain Acumen. Invoice management systems, tax assessment, credit score generation, auditing, future investment, Personal Financial Management etc. Artificial Intelligence finds its utility in all. Moreover, Bionic Advisory gives more efficacious outcomes
\end{abstract}

Index Terms: Accounting, Artificial Intelligence, Bots, Digital Workforce, Finance etc.

\section{INTRODUCTION}

Artificial Intelligence expands the domain of computer from data loader to intelligence recouping. It permits cybernetic organism to deploy solutions over different situations. Theorists believe that AI is of the following types:

1. Artificial Narrow Intelligence

2. Artificial General Intelligence

3. Artificial Super Intelligence

Artificial Intelligence may find its utility over varied disciplines, but it has been believed that it has been an emergence because of the following:

$\begin{array}{ll}\text { 1. } & \text { Philosophy } \\ \text { 2. } & \text { Mathematics } \\ \text { 3. } & \text { Cognitive Science } \\ \text { 4. } & \text { Biology } \\ \text { 5. } & \text { Psychology } \\ \text { 6. } & \text { Neuroscience } \\ \text { 7. } & \text { Evolution etc. }\end{array}$

Accounting, on the other hand, is the systematic process of recording, classifying and summarising business transactions. Types of accounting are the following:

$\begin{array}{ll}\text { 1. } & \text { Financial Accounting } \\ \text { 2. } & \text { Managerial Accounting } \\ \text { 3. } & \text { Fiduciary Accounting } \\ \text { 4. } & \text { Cost Accounting } \\ \text { 5. } & \text { Forensic Accounting } \\ \text { 6. } & \text { Auditing } \\ \text { 7. } & \text { Taxation } \\ \text { 8. } & \text { Accounting Information System }\end{array}$

Revised Manuscript Received on October 22, 2019.

Reepu, Assistant Professor, University School of Business Chandigarh University, Gharuan, India. Email:

reepu.technowize@gmail.com

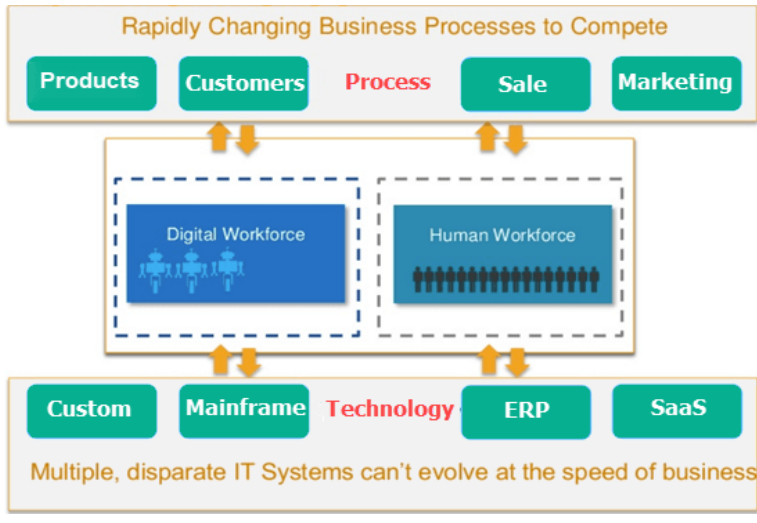

Fig. 1: Present day digital landscape

Workplace, today do not just encompasses human workforce. Drastically changing trends require the assistance as well as collaboration of many. The current digital landscape can be inferred with the help of following diagram:

As per the diagram, both digital as well human workforce exists as an interface. Enterprise Resource Planning (ERP) tends to integrate different organizational functions. Human Workforce is indulged in Software as a Service (SaaS) also, and works on the subscribed software. On the other hand, bulk processing is handled by mainframe and both, customary applications as well as mainframe are administered by Digital Workforce. Thus, human as well as digital workforce integrates for product selling in order to attain large market share.

\section{RESEARCH OBJECTIVE}

After delineating the compendious contour about artificial intelligence in finance and accounting, covering both theoretical as well as practical aspects, this paper contributes to fill the gap with research docket at multiple channels, in multiple contexts. Several methodological accoutre for AI in finance and accounting paradigms have been explored. Moreover different key trends that are going to generate affluence in the Finance and Accounting domains have also been presented. The present paper aims to understand the artificial intelligence offerings in the paradigm of accountancy and finance.

\section{REVIEW OF LITERATURE}

Duchessi P et al (1993) have discussed the interlinkage of different management disciplines with Artificial Intelligence. Hence, it can be intercepted that theorists over that time period only have begun to analyse the linkages for the same as they believed that AI will have judicious impact over different streams. Bench T.J.M (2007) researched that argumentation have become a staple study of AI. 
In this paper, author has established the linkage of classical argumentation concept with the conventional logical reasoning concepts. Capon T.J.M.Bench et al (2007) have studied the archaic issues in $\mathrm{AI}$, in order to demarcate between the previous as well as upcoming modules. Johnson B.G et al (2008) describes the usage of Artificially Intelligent Tutor, one who yields instructions about accounting cycle. They found that students who used such systems have improved their accounting scores. Issa et al (2016) found that auditing has progressed with the help of artificial intelligence. A sequential set of research-based questions enabled them to generate the status on the AI adaption. Lemaignan S et al (2017) in their research paper have described different challenges which a robot needs to re-work in line with human being. Luo $\mathbf{J}$ et al (2018) have analysed the artificial intelligence applications, changes as well as developments in the accounting industry.

\section{AI FLOWCHART}

Artificial Intelligence, an inspiration drove from a human brain, can learn, unlearn, re-learn and act with the help from categorical algorithms. AI now-a-days refer to different algorithm brackets called as Machine Learning, which are statistically enabled to gauge pattern, from gigantic data. Machine learning is powerful tool enabled with hyper realistic photograph and voice synthesis, alphaGo as well as facial recognition, with one generic idea that is to mimic human brain, in order to succour over hard times. However, AI is continuously evolving; the definition observed today may see some value additions tomorrow. Below is an attempt to understand that if this is Artificial Intelligence with the help of flowchart.

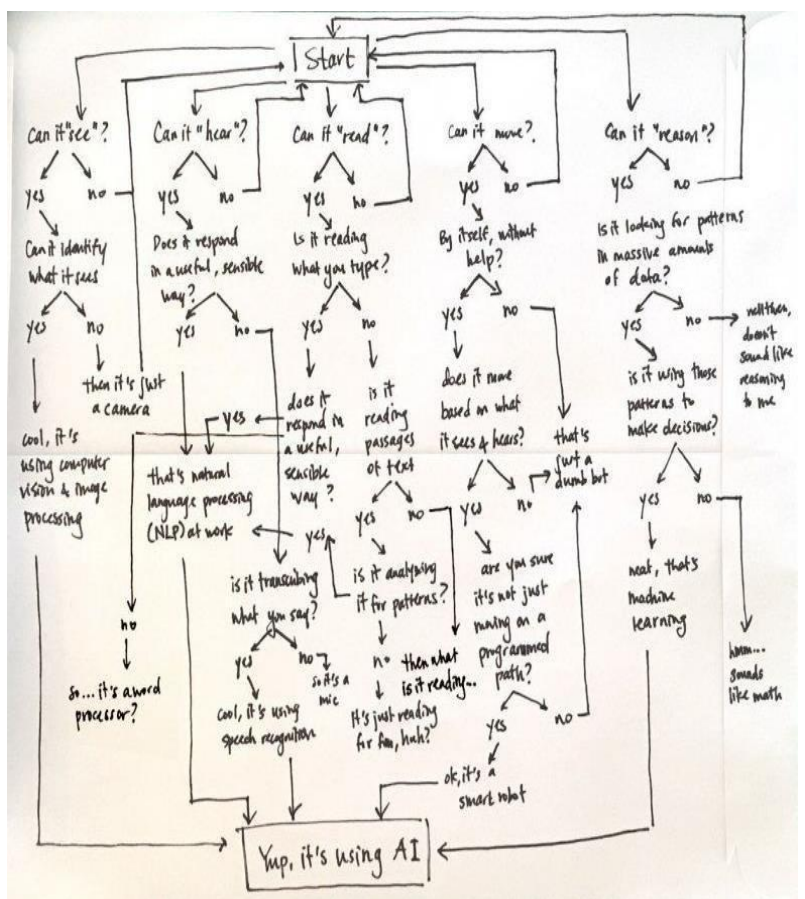

Fig. 2: AI Flowchart

\section{FINDINGS}

\author{
Artificial Intelligence an additive to Human Brain \\ Acumen \\ Following illustrations bolster the said statement:
}

- AI enabled invoice management systems aim to slick the processing of Invoice, but prior knowledge of accounting codes is essential.

- Without the indulgence of human as an entity an AI powered machine can appraise the information pertaining to tax, credit scores etc

- Information about sourcing can be easily structured by a robot. Price change tracker by robot simplifies procurement procedure.

- Audit through digitalization channel assures of $100 \%$ audit because rather than locating some file cabinets, automated audit may assure audit of entire documents. Robotic Process Automation enables digital workforce to work along with human personnel. Following is an illustration of invoice processing

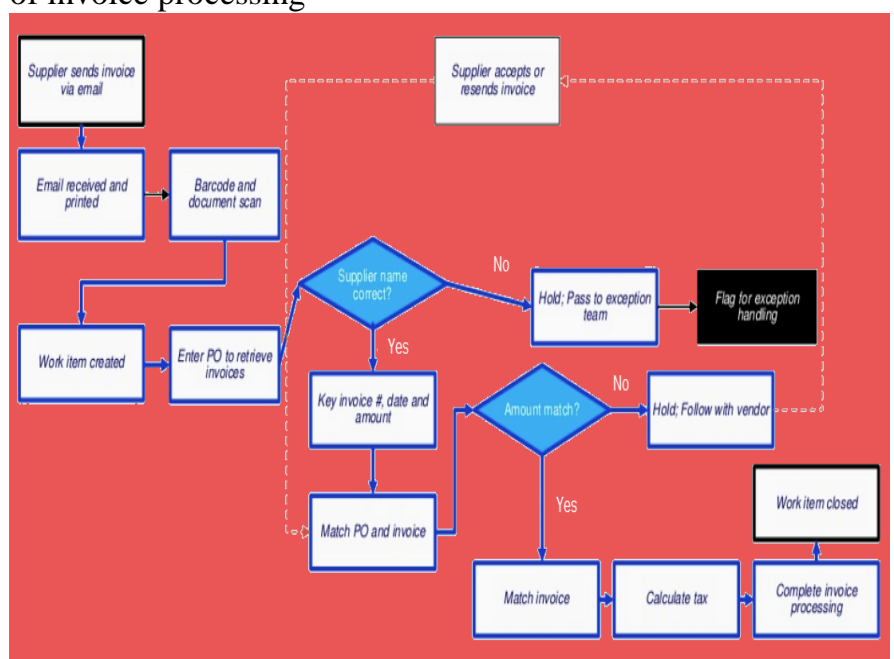

Fig. 3: Example of Robotic Process Automation

- Monthly closure reports can be reconciled in small amount of time, since for machine data compilation is easier as well as speedier.

- Management of expense becomes calculative in a fraction of second. All the receipts, audit expenses are readable by the machine and any contraventions are notifiable.

- Chatbots solve different queries pertaining to account balance as well as account statures.

- As per the reports of Pricewaterhousecoopers, robo-advisors may advice effective measures to advise tax rates etc. Another evolution is bionic advisory which considers the insights given by human being as well as machine calculations.

- Investment may generate adequate returns when the future patterns are adequately administered. Machines may be skilled with effective learnings about different data patterns so that trends can be analysed and hence investments in future may generate appropriate returns. 
- Personal Financial Management is another important feather added to the cap; i.e. present- day AI enabled wallet assures smart decisions. For instance, Wallet created by San Franciso based firm with the help of algorithms, tracks consumer spending through web footprint and generates graph for the same.

Human Cognitive Approach: It has been revealed over by different studies that a human being intends to make decisions either on institution confront or on reasoning basis. Accountants, the fulcrum of an organization use both the basis i.e. he applies his immediate knowledge on that specific situation, but also upshots by making use of his own experience for the same.

Artificial intelligence, on the other hand, possesses the following strengths:

- Processing of large data packets

- Continuously changing patterns processing

- Consistency

Different models may require hefty data processing but definitely not every problem have accurate data to process. Data models can definitely jettison human generated biasness, if any, and undoubtedly, entrench societal biasness. Other side of the story is that not all the problems can be judiciously solved with this as some may require adamant considerations of ethnicity or other valuable suggestions. Therefore, bionic advisory can be more efficacious.

\section{CONCLUSION}

Technology has its utility as well as applications in over diverse fields. Even Finance and Accounting has not been devoid from it. The present paper is an attempt to understand the indulgence of technology into these disciplines. There occur diverse arenas like investment, Personal Finance Management, Expense Management etc. where AI with the usage of its schematic algorithms have been delivered intelligent decisions. But with more of bionic advisory into place, the outcomes will be more effective.

\section{REFERENCES}

1. Duchessi P et al (1993), "A Research Perspective: Artificial Intelligence, Management and Organizations", DOI:10.1002/j.1099-1174.1993.tb00039.x

2 Bench T.J.M (2007), "Argumentation in Artificial Intelligence", https://doi.org/10.1016/j.artint.2007.05.001

3. Capon T.J.M.Bench et al (2007), "Argumentation in Artificial Intelligence, Artificial Intelligence” 171, pp. 619-641.

4. Johnson B.G et al (2008), "An intelligent Tutoring System for the Accounting Cycle: Enhancing Textbook Homework with Artificial Intelligence." http://ssrn.com/abstract=1151791

5. Issa et al (2016), "Research Ideas for AI in Auditing: The Formalization of Audit and Workplace Supplementation", Journal of Emerging Technologies in Accounting, Vol.13, No.2, pp 1-20.

6 Lemaignan S et al (2017), "Artificial Cognition for social human-robot interaction: An implementation", https://doi.org/10.1016/j.artint.2016.07.002Get rights and content

7. Luo J et al (2018), "Analysis of the Impact of Artificial Intelligence Application on the Development of Accounting Industry", Open Journal of Business and Management, vol. 6, pp. 850-856

8 https://www.guru99.com/robotic-process-automation-tutorial.html

9. MIT Technology Review

10 https://www.guru99.com/robotic-process-automation-tutorial.html

\section{AUTHORS PROFILE}

Reepu is working as an Assistant Professor, at University School of Business Chandigarh University, Gharuan, India. Email: reepu.technowize@gmail.com 